\title{
Characterization of Surface Layer Turbulence across a West African Tropical Climate Belt
}

\author{
David 0. Edokpa, Precious N. Ede \\ Department of Geography and Environmental Management, Rivers State University, Port Harcourt, Nigeria \\ Email: onojiede@gmail.com
}

How to cite this paper: Edokpa, D.O. and Ede, P.N. (2020) Characterization of Surface Layer Turbulence across a West African Tropical Climate Belt. Atmospheric and Climate Sciences, 10, 405-420. https://doi.org/10.4236/acs.2020.103023

Received: May 4, 2020

Accepted: June 29, 2020

Published: July 2, 2020

Copyright $\odot 2020$ by author(s) and Scientific Research Publishing Inc. This work is licensed under the Creative Commons Attribution International License (CC BY 4.0).

http://creativecommons.org/licenses/by/4.0/

\begin{abstract}
This study surveyed the levels of boundary layer surface turbulence across a West African climate region. Five years (2011-2015) temperature and wind speed data at synoptic hours $0000 \mathrm{Hr}, 0600 \mathrm{Hr}, 1200 \mathrm{Hr}$ and $1800 \mathrm{Hr}$ within $0.125^{\circ}$ grid resolution was sourced from Era-Interim Reanalysis platform at 1000 mbar pressure level. Using the Richardson $\left(R_{i}\right)$ number technique, results showed that mechanical turbulence of $R_{i}$ range $0.04-0.57$ dominates across the surface layer for study locations of Port Harcourt, Enugu, Jos, Kano and Maiduguri than thermal turbulence. However, the least turbulent area was the coastal zone of surveyed region. Results also indicated that the vertical height $(L)$ at which thermal turbulence replaces mechanical turbulence across study locations ranged from $20-250 \mathrm{~m}$ with lowest replacement levels (20 - $50 \mathrm{~m}$ ) occurring mainly in the coastal area of Port Harcourt during periods of dawn. The most turbulent periods in the southern coastal location of study region were during key rainy periods from June-August while that for the rest far northern inland areas occur during the dry season/early rainy periods i.e. November-May. The implication of the lower surface turbulence/replacement level within coastal domains most especially during periods of dawn is that emission releases near surface layer will be dispersed after initial rise due to buoyancy at horizontal levels thereby increasing ground level pollutants concentration across sensitive receptors that are close to emission source. At heights of thermal turbulence replacement, emission releases will be transported vertically and then dispersed further away from emission sources, thus impacting sensitive receptors at farther distances. This is the atmospheric boundary layer dynamics that makes ground level pollution worse in the coastal city of Port Harcourt in recent times during periods of dawn. Efforts must be made by concerned Stakeholders towards ensuring that emissions are reduced during the periods of dawn within and around coastal environments.
\end{abstract}




\section{Keywords}

Turbulence, Richardson Number, West Africa, Nigeria, Coastal Area, Air

Pollution

\section{Introduction}

The surface layer is the layer in which humans, animals, and vegetation live and where most anthropogenic activities take place. It is the bottom part of the boundary layer that connects the atmosphere to ground surface and is very vital regardless of its lesser share within the overall atmosphere due to its significant turbulent exchanges [1]. The sharpest variations in meteorological variables with height occur within the surface layer and, consequently, the most significant exchanges of momentum, heat, and mass also occur in this layer [2]. Therefore, it is not surprising that surface layer has received far greater attention from meteorologists and climatologists than has the outer part of the atmospheric boundary layer (ABL). Turbulent exchanges processes in the ABL have profound effects on the evolution of local weather. Boundary layer fraction is primarily responsible for low-level convergence and divergence of flow in the regions of lows and high surface pressures, respectively. The frictional convergence in a moist boundary layer is also responsible for low-level convergence of moisture in low-pressure regions. The kinetic energy of the atmosphere is continuously dissipated by small-scale turbulence in the atmosphere. Almost one-half of this loss on an annual basis occurs within the $\mathrm{ABL}$, even though the $\mathrm{ABL}$ comprises only a tiny fraction (less than 2\%) of total kinetic energy of the atmosphere.

Due to geographical and micro-climatic differences, the level of surface layer turbulence varies from one climate zone to another [3]. This difference modifies ways lower atmospheric emissions are transported and dispersed within the boundary layer. The atmospheric surface layer is the active link between the atmosphere and surface and plays a major role in transporting suspended pollutant, water vapour and heat from ground surface. Accurate characterization of turbulent fluctuations in this layer is of great importance towards a successful modeling of large-scale meteorological processes. Reference [4] acknowledged that boundary layer turbulent weather situations play very critical role in the aviation industry. This turbulent condition culminates into flight cancellation and diversion which decreases airliners profit and passengers delay. It was highlighted that the Sosoliso air disaster that occurred at Port Harcourt international airport, Nigeria, in 2005 was ascribed to turbulent weather situation. Surface layer turbulence can be engendered through thermal and mechanical means. While thermally generated turbulence is associated with interrelation between energy fluxes from the sun and ground surface, mechanical turbulence is linked to wind shear. This study examines surface layer turbulence across tropical climate zones in Nigeria using Richardson number $\left(R_{i}\right)$ technique. The 
nitty-gritty of $R_{i}$ technique is that it is based on comparative extent of convective and mechanical instability in atmospheric motions [2]. It defines the qualitative character of turbulence in the boundary layer when detailed measurements are available and set limits for turbulence activation and dissipation. This ensures a viable resolution of turbulence pattern for various surface layer locations.

\section{Effects of Surface Turbulence on Boundary Layer Climate}

A vast portion of solar heat is transferred to the surface where it is transformed and transferred to various portions of the atmosphere by processes taking place in the layer [5]. One of these critical processes is turbulence. Surface layer characteristics as well as energy exchange processes that are significantly enhanced by turbulent mixing determine climate pattern of any locality [6]. The exchange of sensible and latent heat fluxes within earth surface and atmosphere are through turbulence transfers and the heat fluxes modify micro-climatic processes that take place between the atmosphere and ground surface [7]. While turbulence at surface layer is more or less unceasing, the micro-climate condition of any locality depends on intensity and variation of turbulence in modifying surface heat fluxes within boundary layer atmosphere. The energy of dynamic heat fluxes prevalent within the surface averages over $85 \%$ and this makes the surface layer play a major role in transport processes that occur between the planetary layer and upper part of the troposphere [8] [9]. Within the lower troposphere, turbulence controls vertical interactions of all climatic variables such as atmospheric stability, heat and moisture. Roughness of the surface layer affects airflow at the boundary layer as well as interchange of momentum and energy between ground surface and overlaying atmosphere [10]. This brands the surface layer as wind induced instability layer, which acts to transfer fluxes vertically. The magnitude of instability, nevertheless, depends on significant factors such as surface coarseness and atmospheric stability pattern. Since surface layer is the section near ground's surface, a variation in radiation warming or cooling will be initially noticed at the surface before upper atmosphere [11]. The existence or lack of instability at the surface layer determines levels to which creatures are exposed to weather extremes. Due to mixing ability of turbulence, modeling atmospheric planetary layers is relevant for many practical applications. Ranging up to 100 meters in altitude, the surface layer exhibits dynamic properties that influence to a large extent, human activities [12].

\section{Study Area}

The position of Nigeria is principally within lowland moist tropics north of the equator and branded by a high-temperature system [2] [13]. The atmosphere of study area is characterized by two air mass i.e. moist/warm (Ocean inclined) and dry/warm (Sahara desert inclined) air masses separated by a zone of discontinuity known as inter-tropical discontinuity (ITD). The ITD is deep-seated during 
months of June-September in northern part of Nigeria and above $70 \%$ of mean annual rainfall both at the northern and southern areas of Nigeria is reached during these months [14]. The double maxima rainfall experienced in deep coastal south, for instance is as a result of ITD moving northwards during early part of the year, bringing rainfall to peak in June and then returning back southwards later in the year with another round of peak rainfall in September. The high temperature range observed over Nigeria at its latitudinal position is primary because the astronomical variation of insolation is a function of latitude and the daily variation in elevation of the sun is large in low latitude and rather small in high latitudes [15]. High altitude locations such as Jos Plateaux, Adamawa highlands, Obudu and Mambila plateau have a cooler climate than their surrounding lowlands [16]. The lower temperature observed at highlands areas is due to temperature decrease with height and less air pressure that is not able to retain much heat and for longer period. The factors which influence the distribution of temperature at any location in Nigeria include: the amount of insolation received, nature of surface, distance from water bodies, relief, nature of prevailing winds and ocean currents. Therefore, the closer an area is to the ocean, the lower the temperature due to Land and Sea Breeze effect as well as associated trade wind during day periods. This is because diurnal temperature of closer land areas is being modified by Sea Breeze effect. Therefore under this condition, temperature increases as one move inland northwards. However, due to fact that land cools faster than the ocean at night, the reversed pressure gradient ensures that areas closer to the ocean are slightly warm at nights than far inland areas. Under this condition, air temperature of far inland becomes lower than areas close to the ocean at night due to distance from the ocean. Also, during wet

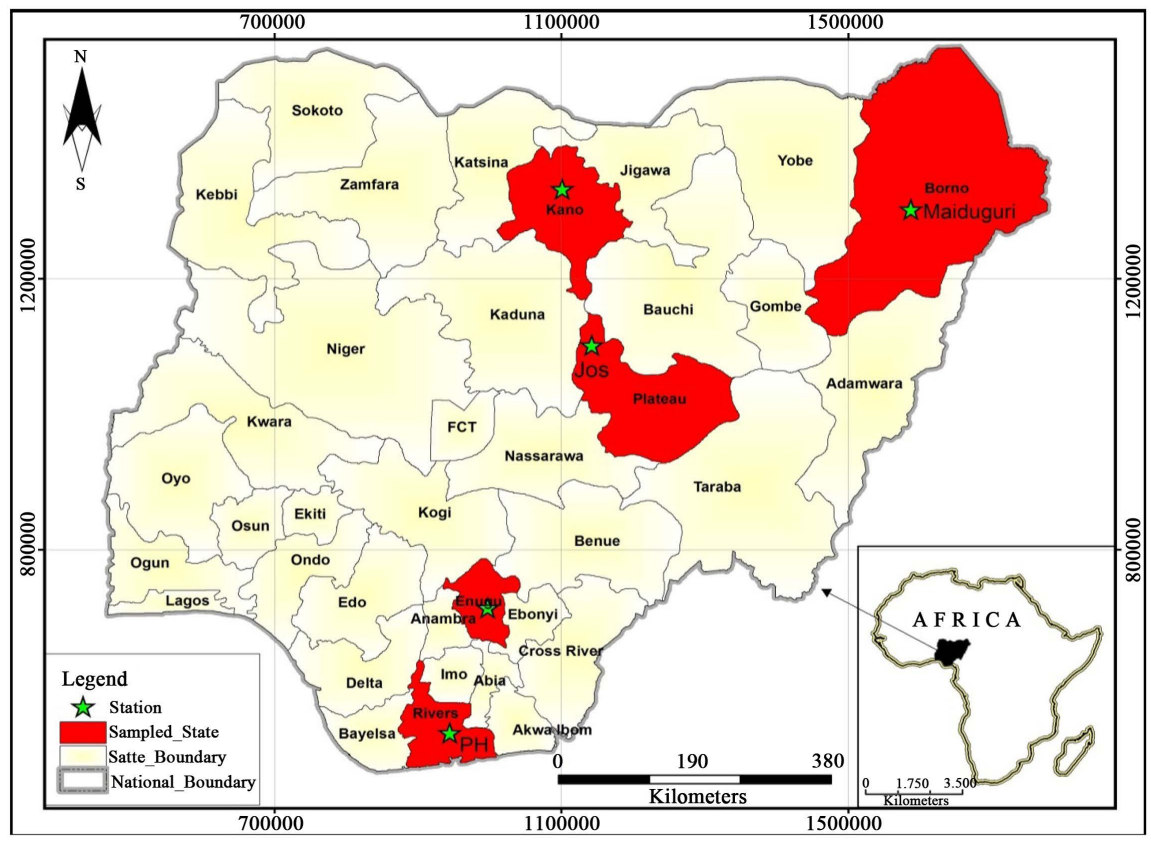

Figure 1. Nigeria, with study areas. Source [2]. 
season, temperatures increase inland towards far north due to more enhanced cloud cover along coastal areas. The efficiency of solar heat is being moderated by cloud cover. Therefore, since cloud cover decreases northwards; solar intensity is very high with resultant increase in diurnal temperature due to dry soil as well as the predominant drier air [15]. Figure 1 shows the map of Nigeria with study areas.

\section{Materials and Method}

Richardson number $\left(R_{i}\right)$ establishes significance of turbulence in the boundary layer. It is a measure of relative influence of turbulent suppression by convective heat transfer compared with turbulence generated by mechanical shear. The numerator is associated to the disrupting forces that engender buoyancy and denominator associated to dynamic energy that terminates buoyancy. Richardson interpreted this as a characteristic of the proportion of work done on gravitational stability to energy transferred from mean to turbulent motion [17].

The turbulent fluxes of momentum and heat at surface layer are determined by vertical profiles of wind speed and temperature within maximum surface layer depth $Z_{1}$ and $z_{2}$. Applying logarithmic finite difference for wind speed and potential temperature profiles, the Richardson number $\left(R_{i}\right)$ at geometric mean height $\left(Z_{m}\right)$, a dimensionless characteristic of atmospheric turbulence, is given by [18]:

$$
\begin{aligned}
R_{i} & =\frac{g}{T_{a}} \cdot \frac{\left(\frac{\mathrm{d} \theta}{\mathrm{d} z}\right)_{z_{m}}}{\left(\frac{\mathrm{d} u}{\mathrm{~d} z}\right)_{z_{m}}^{2}} \\
& =\frac{g}{T_{a}} \cdot \frac{\Delta \theta z_{m}}{(\Delta u)^{2}} \ln \left(\frac{z_{2}}{z_{1}}\right)
\end{aligned}
$$

where,

$g$ : is acceleration due to gravity

$\mathrm{d} \theta / \mathrm{d} z$. is the vertical potential temperature gradient

$T_{a}$ : is absolute temperature $(\mathrm{K})$

$\mathrm{d} u / \mathrm{d} z$ is the vertical wind speed gradient $(\mathrm{m} / \mathrm{s})$

$Z_{m}:$ is the geometric mean which is given by:

$$
z_{m}=\left(z_{1} z_{2}\right)^{\frac{1}{2}}
$$

The factor, $(\mathrm{d} u / \mathrm{d} z)^{2}$ is square of the rate in which wind speed varies with height and it is also relative to the rate at which mechanical shear in the atmosphere creates turbulence. The potential temperature $(\mathrm{d} \theta / \mathrm{d} z)$ can be replaced in Equation (4), given by:

$$
\frac{\mathrm{d} \theta}{\mathrm{d} z}=\frac{\mathrm{d} T}{\mathrm{~d} z}+\Gamma_{d} / m
$$

where " $\Gamma_{d}$ " is the adiabatic lapse rate which is approximately given as " $-0.01{ }^{\circ} \mathrm{C} / \mathrm{m}$ " 
across distances to the mixing height. The potential temperature, " $\theta$ ', can be utilized in place of actual temperature.

Where,

$$
\theta=T_{\text {initial }}-\Gamma\left(Z_{2}-Z_{1}\right)
$$

where " $Z_{1}$ " and " $Z_{2}$ " are reference heights for the initial and final temperature levels. This requires transformation of measured temperature to potential temperature using Equation (3). The Richardson number can now be calculated from measurements of $u$ and $\theta$ at various heights i.e. $(0-50 \mathrm{~m})$. The relationship between Richardson number and Monin-Obukhov Length $(L)$ which defines the height where thermal turbulence replaces mechanical turbulence is given by:

$$
R_{i}=\frac{z_{m}}{L}
$$

The wind estimation equation was used to adjust the observed wind speed, $U_{\text {ref }}$ from a reference measurement height, $H_{r e f}$ to the upper height, $H_{s^{\prime}}$. The equation is of the form [19]:

$$
\frac{U}{U_{r e f}}=\frac{\ln \left(\frac{H}{Z_{o}}\right)}{\ln \left(\frac{H_{r e f}}{Z_{o}}\right)}
$$

where $Z_{o}$ is surface roughness length, $L(\mathrm{~m})$. The assumed length utilised for study areas are shown on Table 1 . Table 2 shows the characteristics of turbulence flow for atmospheric boundary layer.

Table 1. Assumed roughness length across sampled areas.

\begin{tabular}{ccc}
\hline $\begin{array}{c}\text { Roughness Length, } \\
L(\mathrm{~m})\end{array}$ & Landscape Type & Sampled Areas \\
0.03 & $\begin{array}{c}\text { Open agricultural areas and } \\
\text { very scattered building }\end{array}$ & Maiduguri \\
$0.3-0.4$ & $\begin{array}{c}\text { Towns with agricultural, } \\
\text { lands with very coarse and irregular terrain }\end{array}$ & Kano, \\
0.8 & Large Cities with tall buildings & Port Harcourt \\
\hline
\end{tabular}

Source: [19] [20].

Table 2. Characteristics of vertical flow of air for Richardson number values.

\begin{tabular}{cccc}
\hline Richardson Number & $\begin{array}{c}\text { Types of } \\
\text { Flow }\end{array}$ & $\begin{array}{c}\text { Level of Turbulence } \\
\text { Due to Buoyancy }\end{array}$ & $\begin{array}{r}\text { Level of Turbulence } \\
\text { Due to Shear }\end{array}$ \\
\hline Large, Negative & Turbulent & Large & Small \\
Small, Negative & Turbulent & Small & Large \\
Small, Positive & Turbulent & None & Large \\
Large, Positive & Laminar & None & Small
\end{tabular}

Source: [22] 
For Richardson $\left(R_{i}\right)$ number values between 0 and Richardson critical $\left(R_{i c}\right)$ value of 0.25 , turbulent flow is generated mostly by mechanical convection [21]. Large negative $R_{i g}$ values are generated due to thermal convection [22]. The data for this study were obtained from the European Centre for Medium Ranged Weather Forecast (ECMWF) Era-Interim Re-analysis data for periods 2011-2015 at $0.125^{\circ}$ resolution for 6-hourly synoptic interval, i.e., 0000, 0600, 1200 and 1800. Meteorological variables such as wind speed, air temperature and relative humidity were acquired at pressure level of 1000 mbar.

\section{Results and Discussion}

\subsection{Analysis of Richardson Number $\left(R_{i}\right)$ for Study Areas}

Table 3 shows the average surface layer $R_{i}$ values across the study areas and similar to long term turbulence parameter profiles generated from Western U.S. (Table 4).

The results of this study are shown in Figures 2-5. Results analysis shows that surface layer turbulence across the boundary layer in Nigeria is generated due to mechanical turbulence than thermally induced. This is indicated from the estimated Richardson number $\left(R_{i}\right)$ outcome where values were all positive and of smaller magnitudes. It is shown that all dimensionless $R_{i}$ values were within 0.04 - 0.57 for all study locations. Both small positive and negative $R_{i}$ values indicate turbulence majorly due to wind shear while large negative $R_{i}$ values showed turbulence due to thermal buoyancy [22]. Though, lower $R_{i}$ boundary value of 0.04 was lesser than Richardson critical $\left(R_{i c}\right)$ value of 0.25 , the upper boundary number (0.57) was $37 \%$ higher than the $R_{i}$ critical number. However all estimated

Table 3. Average surface layer $(0-50 \mathrm{~m})$ turbulence values for areas.

\begin{tabular}{ccccc}
\hline \multirow{2}{*}{ Areas } & \multicolumn{4}{c}{ Richardson number $\left(R_{i}\right)$ Indicator across Study Areas } \\
\cline { 2 - 4 } & $\mathbf{0 0 ~ H r}$ & $\mathbf{0 6 ~ H r}$ & $12 \mathrm{Hr}$ & $\mathbf{1 8 ~ H r}$ \\
\hline Port Harcourt & 0.24 & 0.46 & 0.25 & 0.32 \\
Enugu & 0.10 & 0.11 & 0.15 & 0.16 \\
Jos & 0.19 & 0.13 & 0.11 & 0.17 \\
Kano & 0.10 & 0.06 & 0.08 & 0.16 \\
Maiduguri & 0.15 & 0.14 & 0.23 & 0.32 \\
\hline
\end{tabular}

Table 4. Long term turbulence parameter for western U.S.

\begin{tabular}{cc}
\hline Height, $Z(\mathrm{~m})$ & Similarity Theory \\
\hline 10 & 0.115 \\
50 & 0.11 \\
100 & 0.08 \\
200 & 0.035
\end{tabular}

Source [23]. 


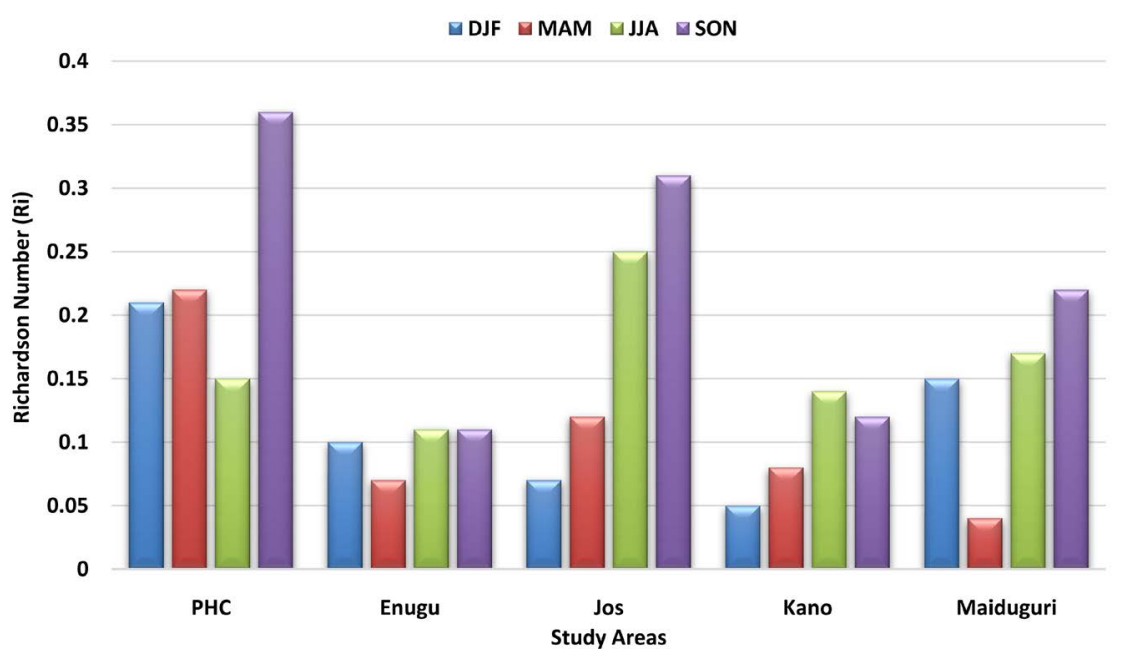

Figure 2. Richardson number $\left(R_{i}\right)$ values at 00:00 $\mathrm{Hr}$.

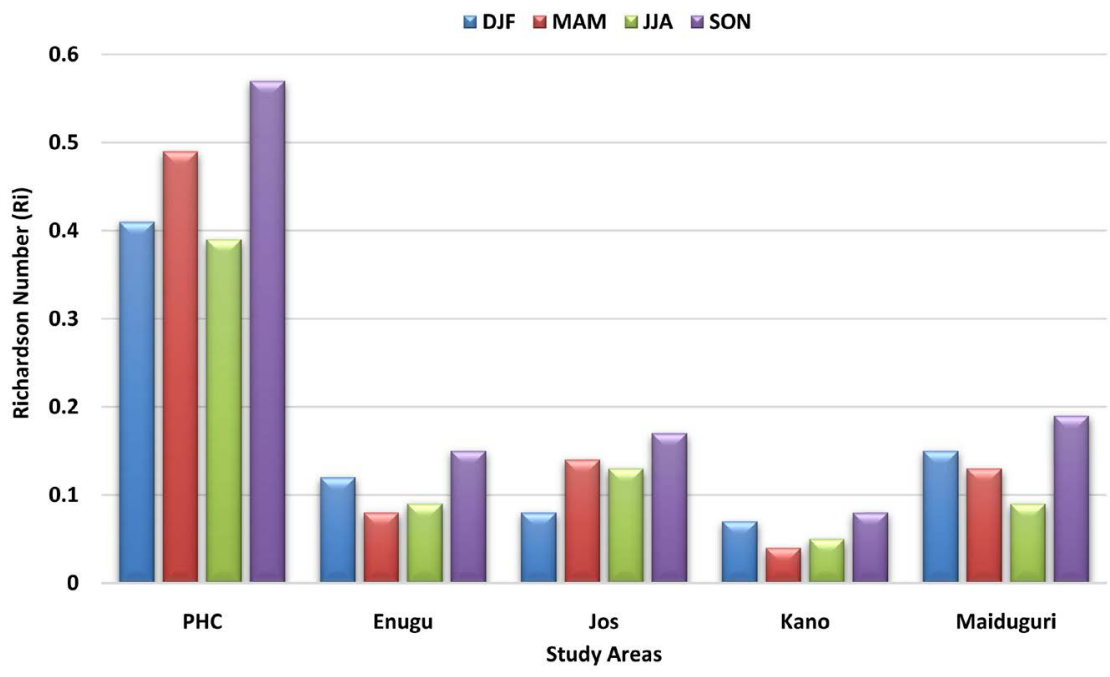

Figure 3. Richardson number $\left(R_{i}\right)$ values at 06:00 $\mathrm{Hr}$.

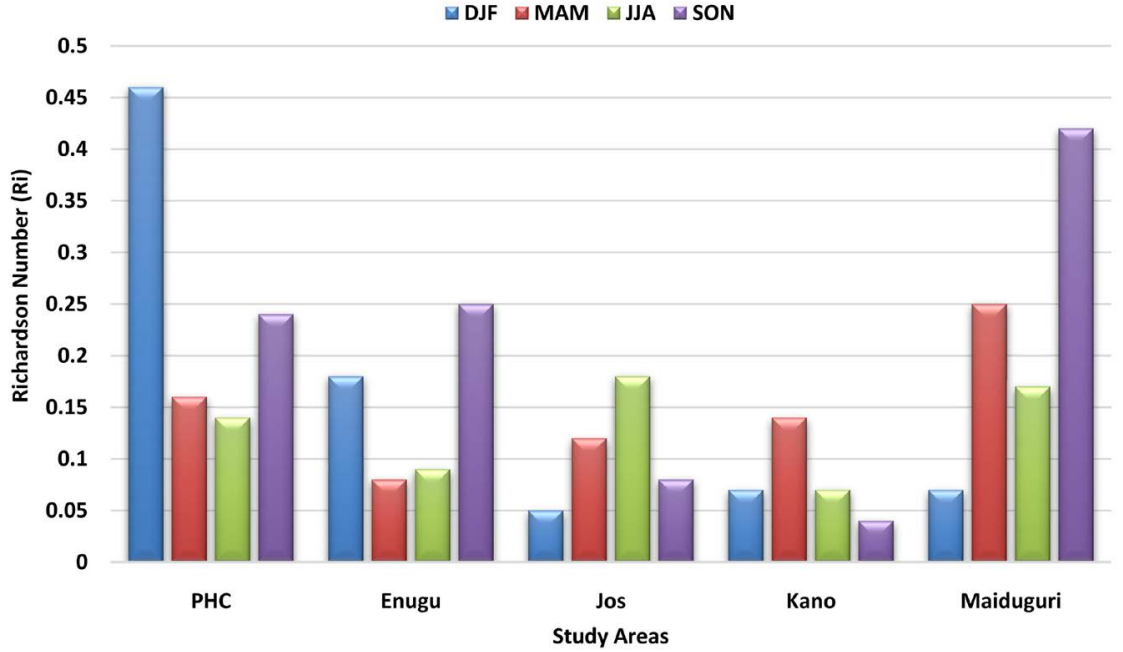

Figure 4. Richardson number $\left(R_{i}\right)$ values at 12:00 $\mathrm{Hr}$. 


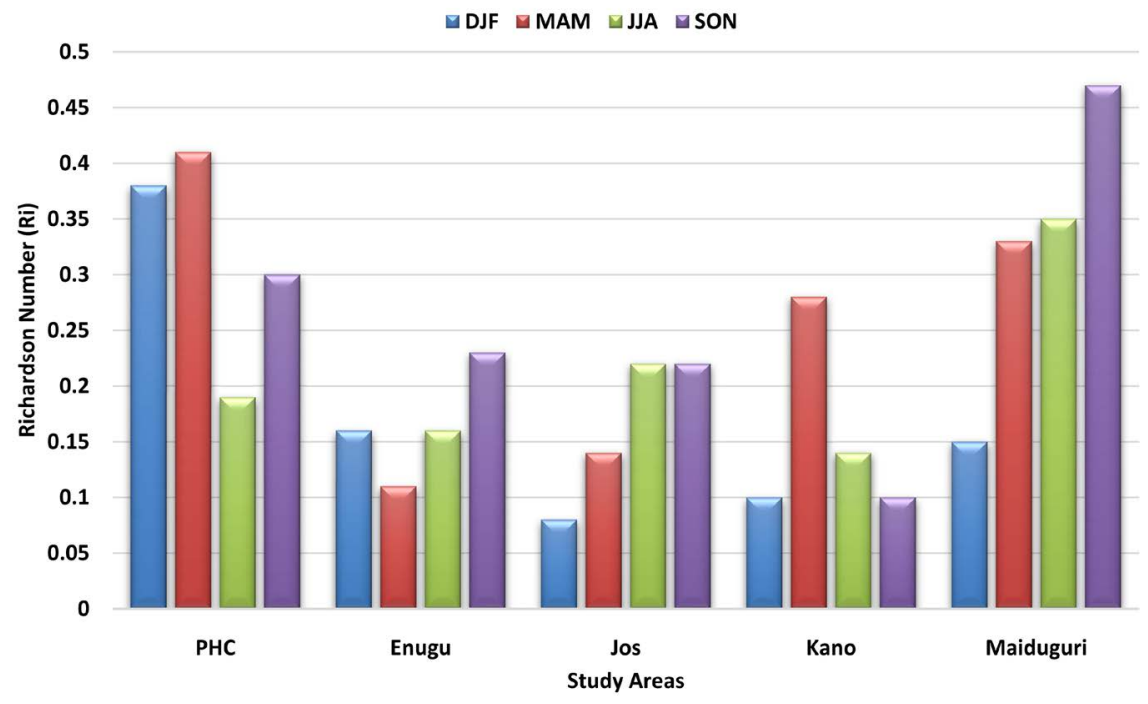

Figure 5. Richardson number $\left(R_{i}\right)$ values at 18:00 $\mathrm{Hr}$.

$R_{i}$ values were lesser than Richardson Termination Level $\left(T_{i T}\right)$ of 1 . It is noted that any flow above the Termination Level becomes lamina [22].

Results also indicated that turbulent eddies varied across the study locations and this is due to the peculiar boundary layer microclimatic characteristics over the locations. Generally, the lowest range of positive $R_{i}$ values was observed in Enugu, Jos, Kano and Maiduguri while the highest range was obtained in Port Harcourt. From the displayed Ri Figures, it was observed that during the 00:00 $\mathrm{Hr}$ period the most turbulent seasons across the study locations were: June-August (Port Harcourt), March-May (Enugu and Maiduguri) and December-February (Jos and Kano). For the 06:00 Hr period, the most turbulent seasons were: June-August (Port Harcourt and Maiduguri), March-May (Enugu and Kano) and December-February (Jos). For the 12:00 Hr period, the most turbulent seasons were: June-August (Port Harcourt), March-May (Enugu), September-November (Kano) and December-February (Jos and Maiduguri). For the 18:00 Hr period, the most turbulent seasons were: June-August (Port Harcourt), March-May (Enugu), September-November (Kano), December-February (Jos, Kano and Maiduguri) see Figures 2-5.

The least turbulent seasons for the locations during the diurnal hours were: 00:00 Hr-June-August (Enugu, Jos and Kano) and September-November (Port Harcourt, Enugu and Maiduguri); 06:00 Hr-September-November (Port Harcourt, Enugu, Jos, Kano and Maiduguri); 12:00 $\mathrm{Hr}-$ March-May (Kano), June-August (Enugu), September-November (Jos and Maiduguri), December-February (Port Harcourt); 18:00 Hr-March-May (Port Harcourt and Kano), June-August (Enugu) and September-November (Enugu, Jos and Maiduguri) see Figures 2-5. During mid-night, Enugu and Kano were more turbulent than the other locations while at 06:00 hour, Port Harcourt was least turbulent than the other locations. At 12:00 and 18:00 hours, Enugu, Jos and Kano were more turbulent than Port Harcourt and Maiduguri. Enugu, Jos and Kano are si- 
tuated in the tropical continental climatic belt where less humid air exists due to the larger diurnal temperature variations that characterized the belt in which both the ground and air are dryer than the tropical wet coastal location of Port Harcourt. The prevalent climatic condition of the tropical continental domains allows for swift navigation of surface layer winds and this enhances mechanical turbulence. Reference [24] noted that higher winds are allied with low relative humidity while light winds are usually allied with high relative humidity.

The least turbulent area of Port Harcourt indicates the prevalence of the humid air mass which accumulates the characteristics of the tropical wet climate condition due to the closeness from the source (Ocean). The humid boundary layer environment is also enhanced by the rate of evapotranspiration resulting from the wet surface as well as the several water bodies surrounding the coastal location. This humid air over Port Harcourt (than the rest study locations) moderates wind shear that lessens mechanical turbulence at the surface layer. Study results showed that the surface layer over Port Harcourt is most turbulent during the first bi-modal periods of rainy season i.e. (June-August). This is indicative of the increased surface layer wind speeds in Port Harcourt during this season due to the rain bearing air mass that sweeps the area. During this season, the ITD is entirely over Nigeria and there is increased instability due to convective activities across the atmospheric boundary layer of Port Harcourt. The average wind speed of Port Harcourt surface layer up to $50 \mathrm{~m}$ is from $0-2.2 \mathrm{~m} / \mathrm{s}$ [2]. Higher values of wind velocity are observed during the June-August season mainly during the afternoon periods. Reference [25] emphasized that atmospheric circulation in the tropics is largely related with low wind speeds of ranges less than $3 \mathrm{~m} / \mathrm{s}$. It was stated that these minimal wind speeds impact significantly on surface layer free convention during the afternoon periods and strong stable conditions in the night time. Port Harcourt is very stable during the early hours of dawn i.e. Pasquill stability (class F) and slightly-moderately unstable (Class C-B) during the daytime periods [26]. The diurnal turbulent trend anomaly noticed between Kano and Maiduguri that are of close proximity in the northern fringes of Nigeria (Figures 2-5) could be linked to the slight latitudinal difference which affects air temperature as well as Lake Chad River close to Maiduguri that tends to increase the moisture content of the atmospheric environment.

\subsection{The Exchange of Mechanical Turbulence/Thermal Turbulence over Study Areas}

Figures 6-9 show the height above the ground surface where thermal turbulence (TT) replaces mechanical turbulence (MT) across the study areas. In the lower tropospheric boundary layer, the structure of turbulence changes with height from the mechanical regime of the surface to the buoyancy regime of the upper layer. This change usually occurs at about $(L)$ which is the Obukhov Length. The change in what drives turbulence production arises steadily since energy fluxes, gradients of wind speeds and temperature all changes easily with altitude across the transition from the ground surface to the upper layer [2]. The structure of turbulence 


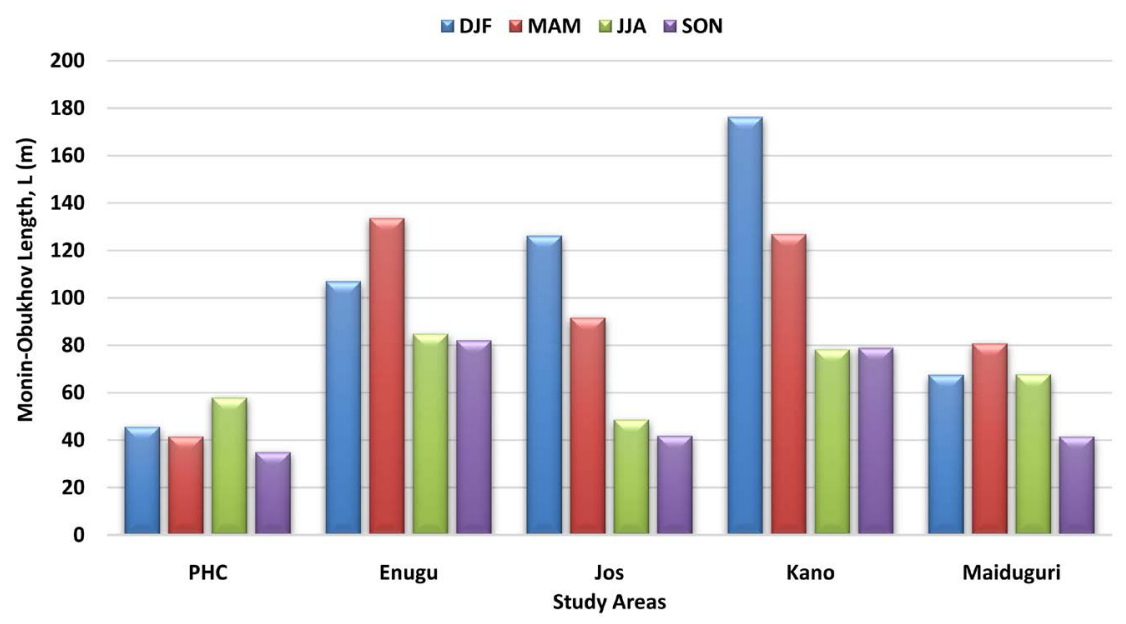

Figure 6. Heights where TT replaces MT at 00:00 Hr.

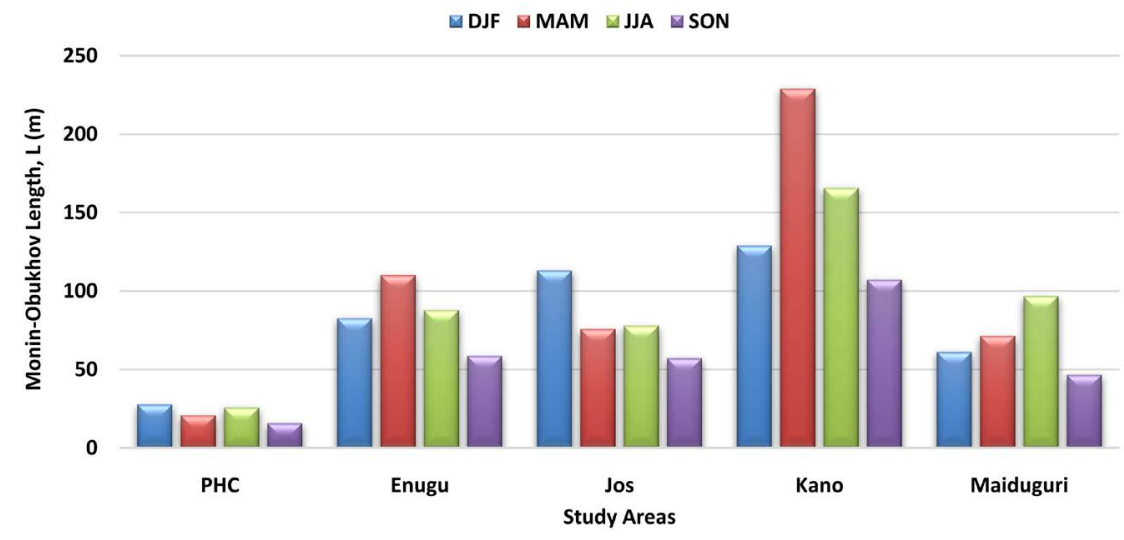

Figure 7. Heights where TT replaces MT at 06:00 Hr.

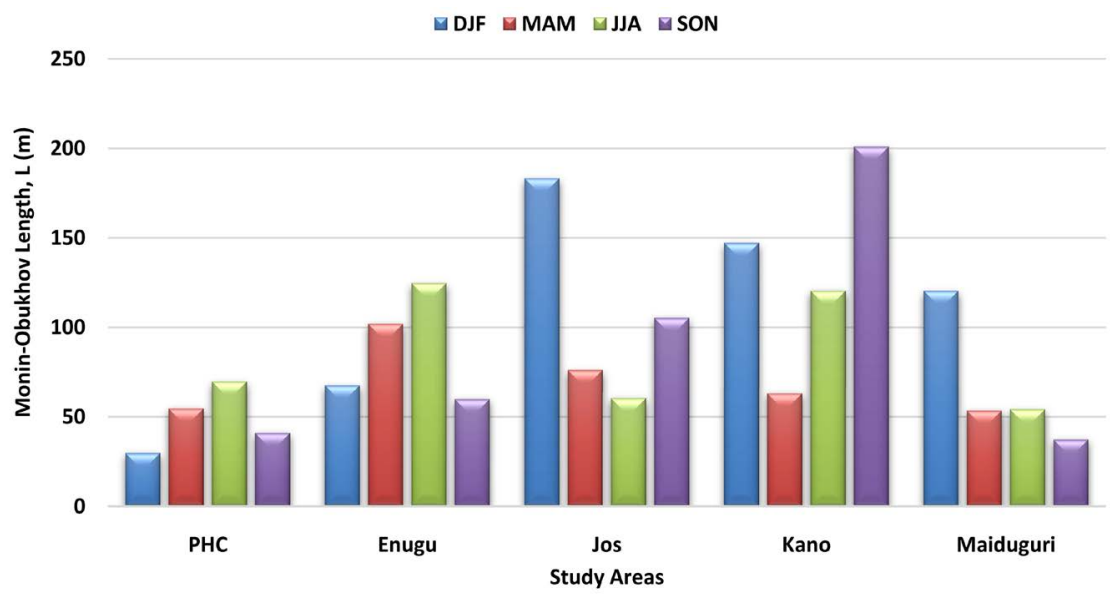

Figure 8. Heights where TT replaces MT at 12:00 Hr.

transforms slowly and increasingly from frictional regime at the surface to a buoyancy regime aloft. It has been shown that mechanical turbulence dominates the surface layers of the entire areas as indicated by the results from the analysed $R_{i}$ values which were small positives (see Table 2) ranging from $0.04-0.57$ 


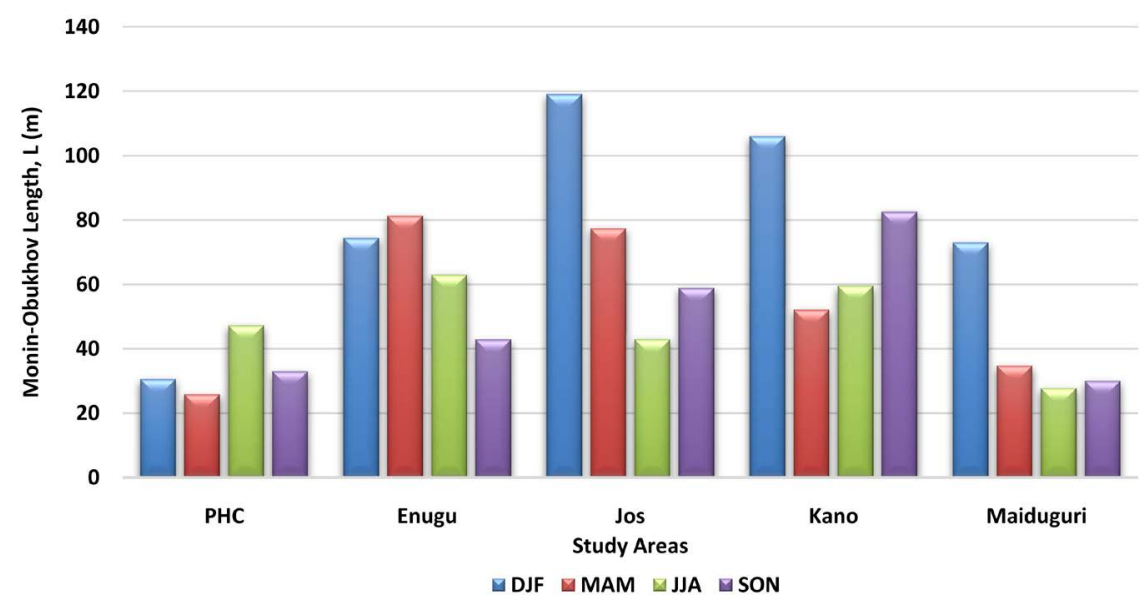

Figure 9. Heights where TT replaces MT at 18:00 Hr.

across the study areas. Generally, results show that the height at which TT replaces MT over the entire study area across the climatic belts was below $250 \mathrm{~m}$ height. The areas with the highest replacement heights were Enugu, Jos and Kano (Figures 6-9). This shows that domains with stronger MT at the surface will have TT replacement at higher heights than areas with low MT at the surface (see Figures 2-5).

Results revealed that Port Harcourt indicated the lowest region where thermal turbulence replaced mechanical turbulence i.e. below $50 \mathrm{~m}$ except during June-August season during the 00:00 and 12:00 hours where it slightly exceeded the $50 \mathrm{~m}$ height (Figure 6 and Figure 8). The lower height of TT replacing MT in Port Harcourt across the diurnal hours is an indication of the smaller diurnal range of ambient air temperature over the area arising from its close proximity to large water bodies which enriches the moisture content of the lower atmosphere than the rest study areas. This smaller temperature variation range ensures the continuous strengthening to a large extent of surface energy fluxes that increases the extent of water vapour in the lower atmosphere thereby increasing the energy content of air. The surface energy fluxes were also influenced by other boundary layer activities that enhance it and these comprise the low cloud cover in the area that traps outgoing terrestrial radiation and returns back to the earth surface, effect of continentality which increases the convective nature of the area, ability of the surface to retain heat for a long time and the degree of vertical mixing as influenced by surface friction. The interactions within these dynamic atmospheric forces enhance thermal stratification which creates turbulence alteration over Port Harcourt lower atmosphere. Reference [15] noted that if the specific heat of any surface is high, more energy will have to be absorbed by the surface to increase surface air temperature.

\subsection{The Implication of Surface Layer Turbulence on Pollutants Dispersion in the Coastal Area of Port Harcourt}

When pollutants from any emission sources are released within the planetary 
boundary layer, its transportation, dilution and dispersion will be determined by the turbulent eddies that characterize the surface layer. Turbulence is a dynamic characteristic of the boundary layer and also the vital force that influences the concentrations of emitted pollutants at sensitive receptors. The lesser the turbulence, the stronger pollutants concentrations will be close to emission sources causing air pollution health hazards as observed in urban and industrialized expanses. The mechanical and thermal exchanges between the surface layer and the lower troposphere prompt a complex stream of energy fluxes that enhances the distributions of air pollutants within the lower troposphere. Reference [27] emphasized these turbulence generating forces that enhance air pollutants dispersion are not mutually exclusive as the mechanical compliments the thermal. However, while the thermal forcing increases the vertical mixing/dilution of air pollutants in the atmosphere, the mechanical forcing enhances the lateral transportation and distribution within the planetary layer. Thus, it is vital to have specific depiction of turbulent flows in pollutants dispersion analysis.

The lower troposphere responds to the diurnal forcing of the surface layer in which turbulence is a principal factor. So, when the earth surface warms or cools due to radiation influence, there are alterations in the dynamic transport process resulting from turbulence modification. The dynamic occurrence of surface turbulence is what distinguishes the surface layer from the mid and upper atmosphere. In this 'scenario, pollutants dilution will now depend on the turbulence mode in transporting the pollutants either horizontally or vertically. The dominant mechanical turbulence generation at the surface within the study areas has shown that horizontal dispersion of air pollutants will be more prominent within the surface layer in the areas. This means that increased emissions from sources at minimal surface layer turbulence will increase pollutants concentrations across sensitive receptors. In as much as the boundary layer is quite variable diurnally in thickness with respect to time from some meters to few kilometers, the impacts of emissions releases from an environment to another will be dependent on the boundary layer mixing height as propagated by the surface layer.

The dominant mechanical turbulence within the surface layer in Port Harcourt which is lesser than the rest study areas as well as its thermal replacement at shorter vertical distance shows that emissions dispersion will be slower at the surface layer and amplified at the mid layer within the Port Harcourt boundary layer than the rest study areas. This is because thermal turbulence increases mixing and hence enhances air pollutants transportation to farther distances away from emission sources. This study results revealed that surface layer turbulence due to wind shear is lowest in Port Harcourt during early hours of dawn i.e. 06:00 hour than the rest study areas. This means that major emission releases from very close distances from the City center during these periods will constitute serious threat to City dwellers. This phenomenon explains the hazards of air pollution that ravage the City areas over the years during the early morning 
hours.

\section{Conclusion}

Pollutants dispersion within the atmospheric boundary layer for any location depends largely on responsive turbulence characteristics of surface layer generated by either thermal or mechanical forcings. This study analyses the turbulence patterns of five locations across the West African region with distinct climate characteristics. These areas which include Port Harcourt, Enugu, Jos, Kano and Maiduguri revealed that mechanical turbulence is dominant across the surface layer, however, with the lowest Richardson values in Port Harcourt. Results also show that the height within the planetary boundary layer where thermal turbulence displaces mechanical turbulence is at a closer range of $0-60 \mathrm{~m}$ within the surface layer in Port Harcourt than the rest study areas. The lowest turbulent periods as shown in this study are during the dawn in Port Harcourt. This indicates that the lower shear rate across the surface layer in Port Harcourt will decrease the transportation of pollutants while the thermal transition at the mid layer will enhance the swift dispersion of pollutants and create more ground level concentrations across sensitive receptors at farther distances from emission sources. The periods with the most intense pollutants concentrations recently in Port Harcourt were during periods of dawn.

\section{Acknowledgements}

The authors of this study appreciate this Journal platform for the opportunity to publish this study.

\section{Conflicts of Interest}

The authors declare no conflicts of interest regarding the publication of this paper.

\section{References}

[1] Chamecki, M., Dias, N.L. and Freire, L.S. (2018) A TKE-Based Framework for Studying Disturbed Atmospheric Surface Layer Flows and Application to Vertical Velocity Variance over Canopies. Geophysical Research Letters, 45, 6734-6740. https://doi.org/10.1029/2018GL077853

[2] Edokpa, O.D. (2018) Atmospheric Stability Conditions of the Lower Atmosphere in Selected Cities in Nigeria. Unpublished Ph.D. Thesis, Department of Geography and Environmental Management, University of Port Harcourt, Nigeria.

[3] Edokpa, O.D. and Weli, V.E. (2017) An Assessment of Atmospheric Boundary Layer Turbulence in Maiduguri, Nigeria. Open Journal of Air Pollution, 6, 27-43. https://doi.org/10.4236/ojap.2017.62003

[4] Weli, V.E. and Emenike, G.C. (2016) Turbulent Weather Events and Aircraft Operations: Implications for Aviation Safety at the Port Harcourt International Airport, Nigeria. International Journal of Weather, Climate Change and Conservation Research, 2, 11-21. http://www.eajournals.org 
[5] Luhunga, P.M. and Mutayoba, E. (2013) Variability of Stability, Momentum and Heat Fluxes in the Stable Boundary Layer over Highveld Priority Area, South Africa. Applied Physics Research, 5, 23-36. https://doi.org/10.5539/apr.v5n4p23

[6] Ramana, M.V., Krishnan, P. and Kunhikrishnan, P.K. (2004) Surface Boundary-Layer Characteristics over a Tropical Inland Station: Seasonal Features. Boundary-Layer Meteorology, 111, 153-175. https://doi.org/10.1023/B:BOUN.0000010999.25921.1a

[7] Högström, U. (1996) Review of some Basic Characteristics of the Atmospheric Surface Layer. Boundary Layer Meteorology, 78, 215-246. https://doi.org/10.1007/BF00120937

[8] Krishnan, P. and Kunhikrishnan, P.K. (2002) Some Characteristics of Atmospheric Surface Layer over a Tropical Inland Region during Southwest Monsoon Period. Atmospheric Research, 62, 111-124. https://doi.org/10.1016/S0169-8095(02)00004-2

[9] Geernaert, G.L. (2003) Surface Layer. https://curry.eas.gatech.edu/Courses/5225/ency/Chapter9/Ency_Atmos/BL_Surface LLayer.pdf

[10] Ayoade, J.O. (2003) Climate Change: A Synthesis of Its Nature, Causes, Effects and Management. Vantage Publishers, Ibadan.

[11] Krishnan, P., Kunhikrishnan, P.K., Nair, S.M., Ravindran, V., Subrahamanyam, D.B. and Ramana, V. (2004) Observations of the Atmospheric Surface Layer Parameters over a Semi-Arid Region during the Solar Eclipse of August 11th, 1999. Journal of Earth System Science, 113, 353-363. https://doi.org/10.1007/BF02716730

[12] Mikkelson, T. (2003) Modeling of Pollutant Transport in the Atmosphere. Atmospheric Physics Division, Wind Department, RISQ National Laboratory, Denmark.

[13] Ulor, C.O. (2012) Assessment of Rainfall Shifts in Qwerri, Nigeria. http://emekahouse.blogspot.com.ng/search/label/Rainfall\%20Trend\%201996-2005

[14] Tarhule, A. and Woo, M. (1998) Changes in Rainfall Characteristics in Northern Nigeria. International Journal of Climatology, 18, 1261-1271.

https://rmgsc.cr.usgs.gov/outgoing/threshold_articles/Tarhule_Woo1998.pdf https://doi.org/10.1002/(SICI)1097-0088(199809)18:11<1261::AID-JOC302>3.0.CO; $\underline{2-Z}$

[15] Ayoade, J.O. (2004) Introduction to Climatology for the Tropics. 2nd Edition, Spectrum Books, Ibadan.

[16] Iloeje, N.P. (2007) A New Geography of Nigeria. 6th Edition, Longman Nigeria Plc, Ikeja.

[17] Sucevic, N. and Djurisic, Z. (2012) Influence of Atmospheric Stability Variation on Uncertainties of Wind Farm Production Estimation. Faculty of Electrical Engineering, University of Belgrade, Serbia. http://proceedings.ewea.org/annual2012/allfiles2/1475_EWEA2012presentation.pdf

[18] Muir, D.M. (2004) Air Pollution Control Technology, Department of Chemical and Process Engineering. University of Strathclyde Publications, UK.

[19] Francisco, B.R., Angeles-Camacho, C. and Sebastian, R.M. (2011) Methodologies Used in the Extrapolation of Wind Speed Data at Different Heights and Its Impact in the Wind Energy Resource Assessment in a Region. In: Suvire, G.O., Ed., Wind Farm-Technical Regulations, Potential Estimation and Siting Assessment, In Tech, London.

[20] Heineman, D. (2011) Wind Energy Meteorology. Energy Meteorology Group. Institute of Physics, Oldenburg University, Germany. 
http://www.slideshare.net/Jupiter276/vl-wind-energymeteorologyss1102

[21] Murty, K.P.R.V., Filho, E.P.M., Prasad, G.S.S.D. and Deane de Abreu Sá, L. (1998) Intercomparison of Flux, Bulk and Gradient Richardson Number and Its Spatial and Temporal Variation as Revealed by Interdisciplinary Pantanal Experiment (IPE-1).

http://www.academia.edu/20968829/Intercomparison_of_flux_bluk_and_gradient_ Richard-

son_number_and_its_spatial_and_temporal_variation_as_revealed_by_interdicipli nary_Pantanal_experiment_IPE-1_may_1998

[22] Jacobson, M.Z. (1999) Fundamentals of Atmospheric Modelling. University Press, Cambridge.

[23] Bowen, B.M. (2008) Analysis of Turbulence Profiles from Three Tall Towers: Departure from Similarity Theory in Near-Neutral and Stable Conditions. The Open Atmospheric Science Journal, 2, 106-116. https://doi.org/10.2174/1874282300802010106

[24] Aiyelabegan, A.T. (2014) Latitudinal Dependence of some Meteorological Parameters in Nigeria. International Journal of Technical Research and Applications, 2, 7-10.

[25] Agarwal, P., Yadav, A.K., Gulati, A., Raman, S., Rao, S., Singh, M.P., Nigam, S. and Reddy, N. (1995) Surface Layer Turbulence Processes in Low Wind Speeds over Land. Atmospheric Environment, 29, 2089-2098. https://doi.org/10.1016/1352-2310(94)00328-I

[26] Edokpa, O.D. and Nwagbara, M.O. (2017) Atmospheric Stability Pattern over Port Harcourt, Nigeria. Journal of Atmospheric Pollution, 5, 7-19.

[27] Vallero, D.A. (2019) Air Pollution Dispersion Models: In "Pollutant Dispersion", Science Direct.

https://www.sciencedirect.com/topics/earth-and-planetary-sciences/pollutant-dispe rsion 